Published in final edited form as:

Am J Kidney Dis. 2010 February ; 55(2): 269. doi:10.1053/j.ajkd.2009.09.021.

\title{
Sleep and Fatigue Symptoms in Children and Adolescents With CKD: A Cross-sectional Analysis From the Chronic Kidney Disease in Children (CKiD) Study
}

\author{
Maria-Eleni Roumelioti, MD ${ }^{1}$, Alicia Wentz, MA ${ }^{2}$, Michael F. Schneider, MS ${ }^{2}$, Arlene C. \\ Gerson, MD PhD ${ }^{3}$, Stephen Hooper, PhD ${ }^{4}$, Mark Benfield, MD ${ }^{5}$, Bradley A. Warady, MD ${ }^{6}$, \\ Susan L. Furth, MD PhD ${ }^{3}$, and Mark L. Unruh, MD MSc ${ }^{1}$
}

${ }^{1}$ Renal-Electrolyte Division, University of Pittsburgh Medical Centre, Pittsburgh, PA ${ }^{2}$ Department of Epidemiology, Johns Hopkins Bloomberg School of Public Health, Baltimore, Maryland ${ }^{3}$ Department of Pediatrics, Johns Hopkins University School of Medicine, Baltimore, Maryland ${ }^{4}$ Department of Psychiatry and Clinical Center for the Study of Development and Learning, University of North Carolina, Chapel Hill, NC ${ }^{5}$ Department of Pediatrics, University of Alabama at Birmingham, School of Medicine ${ }^{6}$ Department of Pediatrics, Children's Mercy Hospital, Kansas City, MO

\section{Abstract}

Background-Although symptoms of sleepiness and fatigue are common among adults with Chronic Kidney Disease (CKD), little is known about the prevalence of these symptoms in children with CKD.

Study Design-Cross-sectional analysis within a cohort study.

Setting \& Participants-We describe the frequency and severity of sleep problems and fatigue, and we assess the extent of their association with measured glomerular filtration rate (mGFR) and Health-Related Quality of Life (HRQOL) among 301 participants of the Chronic Kidney Disease in Children cohort.

Outcomes and Measurements-Sleep and fatigue-related items from the Pediatric Quality of Life Inventory 4.0 Generic Scales and the CKD-related Symptoms List were used.

Results-Median mGFR was $42.0 \mathrm{ml} / \mathrm{min} / 1.73 \mathrm{~m}^{2}$ (25th-75th percentiles, 31.2-53.2) [EF1] and median age was 13.9 years (25th-75th percentiles, 10.8-16.2). Children with mGFR 40-<50, 30$<40$, or <30 had 2.07 (95\% CI, 1.05-4.09), 2.35 (95\% CI 1.17, 4.72) and 2.59 (95\% CI 1.15, 5.85) higher odds of having more severe parent reports of low energy than children with mGFR $\geq 50$.

(C) 2009 The National Kidney Foundation, Inc. Published by Elsevier Inc. All rights reserved.

Corresponding author: Maria-Eleni Roumelioti MD, University of Pittsburgh Medical Center, Renal-Electrolyte Division, 200 Lothrop Street, PUH C-1111, Pittsburgh, PA 15213, Telephone: 412-647-2571, Fax: 412-647-4787, mar127@ pitt.edu.

Publisher's Disclaimer: This is a PDF file of an unedited manuscript that has been accepted for publication. As a service to our customers we are providing this early version of the manuscript. The manuscript will undergo copyediting, typesetting, and review of the resulting proof before it is published in its final citable form. Please note that during the production process errors may be discovered which could affect the content, and all legal disclaimers that apply to the journal pertain.

Financial Disclosure: None.

Supplementary Material

Item S1: CKiD Symptoms List

Table S1: Univariate Relationships between Pediatric Quality of Life Inventory outcomes and cohort characteristics

Table S2: Univariate Relationships between Child report of CKD-related symptoms and cohort characteristics

Note: The supplementary material accompanying this article (doi: ) is available at www.ajkd.org. 
Compared to participants with mGFR $\geq 50$, those with mGFR $<30$ had 3.92 (95\% CI 1.37, 11.17) higher odds of reporting more severe weakness, and those with mGFR 40-<50 had 2.95 (95\% CI $1.26,6.88$ ) higher odds of falling asleep during the day. Low energy, trouble sleeping and weakness were associated with lower HRQOL scores.

Limitations-Symptoms of sleep and fatigue represent the child or parent's perception of symptom severity, while individual items can lead to imprecise measurements of sleep and fatigue.

Conclusions-Lower mGFR was associated with increased weakness, low energy, and daytime sleepiness. Furthermore, a strong association between trouble sleeping, low energy and weakness with decrements in overall HRQOL was observed. Detection and treatment of poor sleep and fatigue may improve the development and HRQOL of children and adolescents with CKD.

\section{Index words}

children; adolescents; chronic kidney disease; sleep; fatigue; glomerular filtration rate; health-related quality of life

\section{Introduction}

Chronic Kidney Disease (CKD) and its consequences are a public health concern, as many children currently being treated for CKD are progressing to End Stage Renal Disease (ESRD). In parallel, more attention is being paid to the educational, psychosocial, emotional and physical health of children and adolescents with CKD (1). Health and growth in children is promoted by adequate sleep, and previous work indicates that sleep problems are prevalent among children with chronic illnesses (2). One of the most compelling reasons why a better understanding of symptoms of sleepiness and fatigue should feature prominently in the care of children with CKD, is that sleep disturbances can have a deleterious effect on a child's behavior, ability to learn and physical development (3).

While sleep and fatigue symptoms have been widely documented among adults with CKD and ESRD (4), assessment of sleep and fatigue problems in children with CKD has been limited. One study demonstrated that $86 \%$ of children and young adults with ESRD on dialysis had a sleep problem (5), while another study of children with CKD stages 1-4 found an increased prevalence of restless legs syndrome (35\%) compared to children without CKD (6). The paucity of data on the prevalence and correlates of sleep and fatigue symptoms in children with mild to moderate CKD provides the impetus for this report, which uses data collected from the Chronic Kidney Disease in Children (CKiD) study, a large North American cohort of children and adolescents with mild to moderate CKD (7). Since many conditions that increase the risk of sleep disturbances and fatigue in children on dialysis (e.g., uremia, anemia, inadequate iron stores, malnutrition, edema and acidosis) are also present among children with mild to moderate CKD (1,8-13), we hypothesized that CKD severity, as quantified by measured glomerular filtration rate (mGFR), would be associated with symptoms of sleep problems (having trouble sleeping, waking up too early, falling asleep during the day and decreased alertness) and aspects of fatigue (low energy and weakness). Furthermore, we examined the extent to which sleep and fatigue symptoms were associated with poorer health-related quality of life (HRQOL) hypothesizing that sleep and daytime functioning are associated.

\section{Methods}

\section{Study Population}

Eligible participants for the CKiD study were 1-16 years of age with mild to moderate CKD, (GFR between 30 and $90 \mathrm{ml} / \mathrm{min} / 1.73 \mathrm{~m}^{2}$ by the Schwartz formula) (14). This report presents cross-sectional data from patients older that 8 years old at the first annual follow-up visit which 
was the first time HRQOL and CKD-related symptoms data were collected concurrently. The age cutoff was chosen in order to facilitate self-report testing with the HRQOL measurement. Demographics, height, weight, vital signs, iohexol-based measurements of GFR $(15,16)$, medical history and medication use were simultaneously obtained. The CKiD study was approved by the Human Subjects Review Boards at all participating sites in the United States and Canada.

\section{Primary Outcomes}

Aspects of HRQOL were assessed with the Pediatric Quality of Life Inventory Version 4.0 Generic Scales (PedsQL), an instrument specifically developed to evaluate the physical, school, emotional and social domains of HRQOL in children that has been previously validated in healthy and patient populations $(17,18)$. The individual items of "having trouble sleeping" from the PedsQL emotional domain and "low energy level" from the PedsQL physical domain were extracted from both the child and parent surveys in order to evaluate the prevalence of sleep problems and fatigue, respectively. The frequency of having trouble sleeping and low energy within the past month was classified into one of four categories: "never"; "almost never"; "sometimes"; "often/almost always". Overall PedsQL scores range from 0 to 100 with higher scores denoting better quality of life. The PedsQL was also scored without the "low energy" and "trouble sleeping items" from both the parent and child surveys. No substantial changes were observed in the internal consistency and reliability (Cronbach alpha) with the removal of these two items from the PedsQL Physical and Emotional domains.

The prevalence of sleep problems and fatigue was also determined by the CKiD Symptoms List (Item S1, provided as online supplementary material available with this article at www.ajkd.org) which was adapted from the Chronic Renal Insufficiency Cohort (CRIC) Study (19). Participants and/or parents were instructed to indicate the number of days in the last month in which they/or their child had experienced any of the following symptoms: "weakness", "waking up early", "falling asleep during the day," or "decreased alertness." If the response exceeded 0 days, the participant and/or parent rated the level of severity as: "mild"; "moderate - severe." Reports of 0 days were classified as "no symptoms".

Sleep symptoms were quantified by reports of having trouble sleeping, waking up early, falling asleep during the day, and decreased alertness. Presence of fatigue was assessed by reports of low energy level and weakness.

\section{Primary Exposure and Covariates}

The primary exposure was mGFR determined by plasma disappearance of iohexol in a twocompartment system measured at 10,30,120, and $300 \mathrm{~min}$ after infusion. Iohexol is a safe, nonionic, low-osmolar contrast agent of molecular weight $821 \mathrm{Da}^{\mathrm{used}}{ }_{[\mathrm{ND} 2]}$ as a filtration marker of the kidneys. It is not secreted, metabolized, or reabsorbed by the kidney (20-22), and has $<2 \%$ plasma protein binding $(20,23)$ and nearly negligible extrarenal clearance (2426). In all analyses, four mGFR categories were utilized: $\geq 50,40-<50,30-<40$ and $<30 \mathrm{ml} /$ $\mathrm{min} / 1.73 \mathrm{~m}^{2}$. Blood samples were collected at the time of the study visit and analyzed at the Central Biochemistry Laboratory (University of Rochester, Rochester, NY). A complete blood count was also obtained locally.

Covariates included ( 1 ) demographic factors: age ( $8-\leq 11,11-\leq 14,14-\leq 16$, and $>16$ years), sex, race (White, African-American), income of primary household members $(\leq \$ 36,000, \$ 36,001$ to $\$ 75,000$, and $>\$ 75,000)$; (2) CKD-related factors: percent of life with CKD $(<25 \%, 25 \%$ $<75 \%, 75 \%-100 \%$ ), primary cause of CKD (glomerulonephritis, non-glomerulonephritis),; (3) growth markers: low birth weight $(<2500 \mathrm{~g}, \geq 2500 \mathrm{~g})$, age and sex specific body mass index (BMI) percentiles ( $<35^{\text {th }}, 35$ th $-<60^{\text {th }}, 60$ th $-<85^{\text {th }}$ and $>85$ th percentile), Tanner Stage (i.e., 
characterization of the physical development of the children and adolescents in this study and was defined by physical measurements of development, based on external primary and secondary sex characteristics, such as the size of the breasts, genitalia, and development of pubic hair) (I-III, IV-V).; (4) Co-morbidities: hypertension (hypertensive $\left[\geq 95^{\text {th }}\right.$ percentile of age-sex-height specific systolic or diastolic blood pressure, or as self-reported hypertension plus current treatment with antihypertensive medications], not hypertensive) $(27,28)$, anemia (hemoglobin level $<11 \mathrm{~g} / \mathrm{dL}$, v.s. $>11 \mathrm{~g} / \mathrm{dL}$ ) (29); and (5) current medication use: antihypertensives, central nervous system (CNS) stimulating agents and antidepressants.

\section{Statistical Analyses}

Non-parametric statistics (e.g., medians, 25th-75th percentiles) as well as percentages were used to describe the characteristics of the study population. Unadjusted and adjusted ordinal logistic regression models were used to quantify the degree of association mGFR and each of the covariates had with the sleep and fatigue outcomes. Covariates were included in adjusted models for a particular outcome if they were significant at the 0.1 significance level in unadjusted analysis for that outcome.

In order to assess the association of sleep problems and fatigue on overall HRQOL, linear regression was used with the child and parent overall PedsQL scores as the response variables and the individual sleep and fatigue item responses as the exposures. Each linear regression model contained an intercept corresponding to the mean response of the reference group and regression coefficients corresponding to the mean differences in responses between each group and the reference group. All analyses were adjusted for age, sex, mGFR stage, income, percentage of life with CKD, BMI percentile, low birth weight, hypertension, and anemia, and were performed using SAS 9.1 statistical software (SAS Institute, www.sas.com).

\section{Results}

\section{Characteristics of Study Population}

As of February 2009, 568 participants completed their baseline study visit and 444 (78\%) completed their first annual follow-up visit. Of the 444, 341 (77\%) were at least 8 years of age at their first annual follow-up visit; among whom 323 (95\%) had data available for at least one HRQOL or CKD-related outcome of interest. The final study population for the present study consisted of 301 (93\%) CKiD participants who also had a valid mGFR at their first follow-up visit.

The 301 participants had a median age of 13.9 years (IQR $10.8-16.2$ ), $61 \%$ were male, $72 \%$ were White, and $60 \%$ were Tanner stage I-III (Table 1). Thirty-six percent of the participants lived in a low-income household and $17 \%$ had low birth weight. The median mGFR was 42.0 $\mathrm{ml} / \mathrm{min} / 1.73 \mathrm{~m}^{2}$ (25t-75th percentiles, $\left.31.2-53.2\right)$ and $23 \%$ had been diagnosed as having glomerulonephritis (GN). The majority of study participants were using antihypertensives (73\%). A small percentage reported using antidepressants (4\%) and CNS stimulating agents $(5 \%)$.

\section{Prevalence of Behavioral Sleep Problems and Fatigue Symptoms}

A total of 263 participants had data available on at least one of the four outcomes: child/parent report of child's trouble sleeping or child/parent report of child's low energy. "Often" or "almost always" was reported for at least one of these outcomes in the past month for $29 \%$ $(\mathrm{n}=75)$ of the study participants. The prevalence of "often" or "almost always" was $12 \%, 9 \%$, $11 \%$, and $14 \%$ for child report of trouble sleeping, parent report of trouble sleeping, child report of low energy and parent report of low energy, respectively (Figure 1). Both child and parent reports of low energy were more frequent for decreased levels of mGFR. Furthermore, 281 
participants reported on at least one of the symptom-related outcomes (weakness, waking up early, falling asleep during the day, and decreased alertness). "Moderate" or "severe" was recorded for at least one of these outcomes for $25 \%(\mathrm{n}=69)$ of the participants. The prevalence of "moderate" or "severe" symptoms was $16 \%, 3 \%, 10 \%$ and $4 \%$ for weakness, waking up early, falling asleep during the day and decreased alertness, respectively (Figure 2). The severity of weakness and falling asleep during the day increased for decreased levels of mGFR.

\section{Univariate and Multivariate Analyses of PedsQL Sleep and Fatigue Outcomes}

In the univariate analysis of PedsQL sleep and fatigue outcomes (Table S1, provided as online supplementary material available with this article at www.ajkd.org) parents' report of low energy was inversely associated with mGFR levels. Neither the frequency of childrens' reports of low energy nor trouble sleeping was significantly associated with mGFR level. Parents of patients with an annual family income of $>\$ 75,000$ reported a significantly lower frequency of low energy compared to parents of patients with an annual family income of $<\$ 36,000$. Having CKD for $\geq 25 \%$ of life was associated with a significantly lower frequency of low energy compared to having CKD for $<25 \%$ of life. Anemia was associated with a significantly greater frequency of low energy, while hypertensive patients reported a significantly lower frequency of trouble sleeping. Age, sex, race, type of CKD diagnosis, birth weight, BMI, and Tanner stage were not associated with any of the PedsQL outcomes.

In the multivariate analysis, parents of patients with lower mGFR levels had higher odds, of reporting a greater frequency of low energy than parents of patients with $\mathrm{mGFR} \geq 50 \mathrm{ml} / \mathrm{min} /$ $1.73 \mathrm{~m}^{2}$ (Table 2). However, patients' reports of low energy and both patients' and parents of patients' reports of trouble sleeping were not significantly associated with mGFR levels. Parents of patients with an annual family income of $>\$ 75,000$ reported significantly lower frequencies of both trouble sleeping and low energy compared to parents of patients with an annual family income of $\langle \$ 36,000$. Furthermore, patients with CKD for $\geq 25 \%$ of their life reported significantly less low energy compared to patients with CKD for $<25 \%$ of life.

\section{Univariate and Multivariate Analyses of Chronic Kidney Disease-Related Symptoms of Sleep and Fatigue}

In the univariate analyses of the associations of symptoms of sleep and fatigue (Table S2, provided as online supplementary material available with this article at www.ajkd.org) reports of increased weakness and greater severity of falling asleep during the day were more common in those with $\mathrm{mGFR}<30 \mathrm{ml} / \mathrm{min} / 1.73 \mathrm{~m}^{2}$ than among those with $\mathrm{mGFR} \geq 50 \mathrm{ml} / \mathrm{min} / 1.73 \mathrm{~m}^{2}$. Waking up early and decreased alertness was not associated with mGFR. Participants 14 years of age and older were more likely to report a greater severity of falling asleep during the day than participants 11 years of age and younger. Higher annual family income $(>\$ 36,000)$, a greater percentage of life with $\mathrm{CKD}(\geq 25 \%)$ and a BMI $>85^{\text {th }}$ percentile were significantly associated with less severe weakness, while the presence of anemia was significantly associated with increased weakness.

In the multivariate analysis, patients with $\mathrm{mGFR}<30 \mathrm{ml} / \mathrm{min} / 1.73 \mathrm{~m}^{2}$ were almost four times more likely to report more severe weakness than patients with $\mathrm{mGFR} \geq 50 \mathrm{ml} / \mathrm{min} / 1.73 \mathrm{~m}^{2}$ (Table 3). Patients with mGFR between $40-<50$ were three times more likely to report more severe problems of falling asleep during the day than patients with $\mathrm{mGFR} \geq 50 \mathrm{ml} / \mathrm{min} /$ $1.73 \mathrm{~m}^{2}$. Patients 14 years of age and older were significantly more likely to report more severe problems of falling asleep during the day than patients 11 years of age and younger. Patients from homes with higher annual family incomes were less likely to report severe weakness and falling asleep during the day than patients from low annual income families $(\leq \$ 36,000)$. Patients with CKD for $\geq 25 \%$ of their lifetime were less likely to report severe weakness than patients with CKD for $<25 \%$ of their life. Finally, anemic patients and patients who were born 
$<2500$ g were more likely to report more severe weakness than patients born with a normal weight or non-anemic patients.

\section{Association of Medications with Sleep and Fatigue Items}

While the prevalence of antihypertensive medication use was high (73\%), its use was not related to mGFR level or to any of the sleep and fatigue outcomes. Study participants who reported using antidepressants $(4 \%)$ or CNS stimulating agents $(5 \%)$ reported a greater frequency of trouble sleeping than those who did not report using antidepressants (ORs of 12.74 [95\% CI 3.56, 45.62] and 7.86 (95\% CI 2.19, 28.22) for child report and parent report, respectively) or CNS stimulating agents (ORs of 4.21[95\% CI 1.36,13.02) and 2.76 [95\% CI $0.90,8.43$ ] for child report and parent report, respectively) after adjustment (not shown). None of the significant findings presented in Table 2 and Table 3 were attenuated when participants using antidepressants or CNS stimulating agents were excluded from analyses.

\section{Association of Sleep and Fatigue items with standardized HRQOL outcomes}

Figure 3 depicts the PedsQL mean scores and 95\% confidence intervals for both the parent and child for each of the trouble sleeping and low energy outcome adjusted for age, sex, mGFR stage, income, percentage of life with CKD, BMI percentile, low birth weight, hypertension, and anemia. A report of "often" or "almost always" having trouble sleeping or low energy by either the parent or the child was associated with lower PedsQL scores.

The relationship between children's overall PedsQL mean scores and symptoms of sleep and fatigue after adjusting for age, sex, mGFR stage, income, percentage of life with CKD, BMI percentile, low birth weight, hypertension, and anemia are shown in Figure 4. A report of "moderate" or "severe" weakness was associated with lower quality of life. None of the other symptoms were associated with the childrens' overall PedsQL scores. The aforementioned relations did not substantially change when the PedsQL overall scores were calculated without excluding the "trouble sleeping" and "low energy" items.

\section{Discussion}

This report extends our understanding of symptoms of sleep and fatigue and their correlates in children and adolescents with mild to moderate CKD. In this study of children from the largest prospective cohort of CKD in North America, the prevalence of moderate or severe symptoms of sleep problems or fatigue for at least one of the four CKD-related symptoms was $25 \%$, while the prevalence of "often" or "almost always" having trouble sleeping or low energy was $29 \%$. Impaired mGFR was associated with higher odds of self-reported weakness as well as parent reports of low energy, after accounting for important demographic factors and comorbidities. Falling asleep during the day was the most striking sleep complaint associated with kidney function as it was two to three times more common among those with a low mGFR. On the other hand, an association between problems with waking up too early or having issues with alertness and mGFR was not found. However, some of the odds ratios relating mGFR to waking up early, falling asleep during the day, and decreased alertness suggested a poorer outcome in individuals with lower mGFR. Therefore, the lack of statistical significance may be due to the lack of moderate or severe outcomes observed in our study population. Younger age and a longer duration of CKD were associated with decreased daytime sleepiness and weakness/low energy, respectively. Furthermore, trouble sleeping, low energy and weakness were strongly associated with decrements in overall HRQOL.

In this report fatigue, as quantified by parent report of a child's low energy and weakness, was significantly associated with CKD severity and impaired HRQOL. Fatigue has been defined as a subjective sense of weakness, lack of energy, and tiredness (30). Children with cancer 
define fatigue as a profound sense of being physically tired or having difficulty with body movement (31). Furthermore, adolescents with cancer described fatigue as a changing state of exhaustion that could include physical, mental, and emotional "tiredness" (31). Generally fatigue questionnaires assess general tiredness $(32,33)$, or a child's level of energy for the completion of activities of daily living (34). In patients with CKD, the strength of the association between a low mGFR and fatigue was not attenuated after accounting for demographic factors and comorbidity, suggesting that nephrologists should approach this symptom as a manifestation of uremic exposure or other comorbidities such as anemia, inflammation, and depression (35).

In our cohort, severe weakness had a clinically significant adverse effect on HRQOL, while waking up early, falling asleep during the day, and decreased alertness were not associated with HRQOL. Our findings are in concordance with two other HRQOL studies involving children with ESRD. McKenna et al. conducted a cross-sectional assessment of HRQOL using the PedsQL Generic Core Scale. Data were collected from 20 children with CKD, 12 on maintenance hemodialysis (HD) or peritoneal dialysis (PD) and 27 with renal transplants and were matched with healthy controls. Children with CKD rated their HRQOL lower than the healthy controls (36). In another study by Goldstein et al., PedsQL data were obtained from 96 pediatric patients with ESRD receiving HD, PD or with a transplant. These participants were then compared to healthy children ( $n=131$ child report; $n=145$ parent report) to assess their HRQOL. For all domains, HRQOL scores for the ESRD patients were significantly lower than healthy controls (37). Timely assessment and treatment of symptoms of sleep and fatigue may contribute to a higher level of HRQOL among children and adolescents with CKD.

A surprising finding was the inverse relationship between percentage of life with CKD and symptomatology, with the inconsistent association between worsening mGFR and symptomatology by parent report. We speculate that patients with a longer duration of CKD had more time to adapt and cope with their disease. In addition, patients with genitor-urinary causes of CKD tend to progress at a slower rate and are exposed to fewer immunosuppressive medications (38). Similar to findings in the adult CKD population, anemia was independently associated with weakness. This finding is particularly interesting given the median hemoglobin of $12.6 \mathrm{~g} / \mathrm{dL}$ and merits further study.

The findings of this report should be interpreted in light of several limitations. First, this report uses items drawn from two questionnaires of the CKiD study to assess aspects of sleep and fatigue. Use of individual items rather than scales may result in imprecise measurements of sleep and fatigue. However, these items have face validity and are similar to items used in sleep and fatigue scales for children and adolescents $(31,39)$. Future work should consider extending these findings by using a combination of validated assessment measures of sleep disorders and fatigue $(40,41)$ and by objective measures, such as actigraphy and polysomnography. Second, the CKiD symptoms checklist was not validated in children with CKD. However, the items have face validity and a $99 \%$ response rate suggesting that the respondents understood the items. Third, the cross-sectional nature of our study precluded us from examining the association of CKD progression with the outcomes of interest. Lastly, rather than a clinical diagnosis, symptoms of sleep and fatigue represent the child's or parent's subjective perception of symptom severity, health and well-being.

In conclusion, this report describes the extent to which sleep and fatigue symptoms are reported by children and adolescents with mild to moderate CKD, showing a greater prevalence of sleep problems and fatigue compared to the general population (42-45). Unlike adults, who have completed their physiologic and intellectual maturation, children are in formative stages of development and therefore are particularly vulnerable to the adverse effects of CKD and sleep deprivation. Early detection and aggressive management of sleep problems and daytime fatigue 
have the potential to markedly improve functional outcomes and HRQOL in young patients with CKD. The findings of our study should be useful for clinicians who care for children and adolescents with CKD, as they may suggest interventions to modify preventable risk factors for poor sleep and fatigue or interventions to lessen their impact.

\section{Supplementary Material}

Refer to Web version on PubMed Central for supplementary material.

\section{Acknowledgments}

Data in this manuscript were collected by the CKiD prospective cohort study with clinical coordinating centers at Children's Mercy Hospital and the University of Missouri - Kansas City and Johns Hopkins School of Medicine (Principal Investigators Bradley Warady, MD and Susan Furth, MD PhD respectively), and data coordinating center at the Johns Hopkins Bloomberg School of Public Health (Principal Investigator, Alvaro Muñoz, PhD). The CKiD website is located at http://www.statepi.jhsph.edu/ckid.

Support: The CKiD study is funded by the National Institute of Diabetes and Digestive and Kidney Diseases, with additional funding from the National Institute of Neurological Disorders and Stroke, the National Institute of Child Health and Human Development, and the National Heart, Lung, and Blood Institute (grants UO1-DK-66143, UO1DK-66174, and UO1-DK-66116). Preparation of this article was supported by the Norman S. Coplon extramural grant program of Satellite Healthcare, Inc.

\section{References}

1. Gerson AC, Butler R, Moxey-Mims M, et al. Neurocognitive outcomes in children with chronic kidney disease: Current findings and contemporary endeavors. Mental retardation and developmental disabilities research reviews 2006;12(3):208-215. [PubMed: 17061289]

2. Ward TM, Brandt P, Archbold K, et al. Polysomnography and self-reported sleep, pain, fatigue, and anxiety in children with active and inactive juvenile rheumatoid arthritis. Journal of pediatric psychology 2008 Apr;33(3):232-241. [PubMed: 18073234]

3. Stores G. Children's sleep disorders: modern approaches, developmental effects, and children at special risk. Developmental medicine and child neurology 1999 Aug;41(8):568-573. [PubMed: 10479046]

4. Murtagh FE, Addington-Hall J, Higginson IJ. The prevalence of symptoms in end-stage renal disease: a systematic review. Advances in chronic kidney disease 2007 Jan;14(1):82-99. [PubMed: 17200048]

5. Davis ID, Baron J, O'Riordan MA, Rosen CL. Sleep disturbances in pediatric dialysis patients. Pediatric nephrology (Berlin, Germany) 2005 Jan;20(1):69-75.

6. Applebee GA, Guillot AP, Schuman CC, Teddy S, Attarian HP. Restless legs syndrome in pediatric patients with chronic kidney disease. Pediatric nephrology (Berlin, Germany) 2009 Mar;24(3):545548.

7. Furth SL, Cole SR, Moxey-Mims M, et al. Design and methods of the Chronic Kidney Disease in Children (CKiD) prospective cohort study. Clin J Am Soc Nephrol 2006 Sep;1(5):1006-1015. [PubMed: 17699320]

8. Fadrowski J, Cole SR, Hwang W, et al. Changes in physical and psychosocial functioning among adolescents with chronic kidney disease. Pediatric nephrology (Berlin, Germany) 2006 Mar;21(3): 394-399.

9. Slickers J, Duquette P, Hooper S, Gipson D. Clinical predictors of neurocognitive deficits in children with chronic kidney disease. Pediatric nephrology (Berlin, Germany) 2007 Apr;22(4):565-572.

10. Gipson DS, Wetherington CE, Duquette PJ, Hooper SR. The nervous system and chronic kidney disease in children. Pediatric nephrology (Berlin, Germany) 2004 Aug;19(8):832-839.

11. Lawry KW, Brouhard BH, Cunningham RJ. Cognitive functioning and school performance in children with renal failure. Pediatric nephrology (Berlin, Germany) 1994 Jun;8(3):326-329.

12. Crittenden MR, Holliday MA, Piel CF, Potter DE. Intellectual development of children with renal insufficiency and end stage disease. The International journal of pediatric nephrology 1985 Oct-Dec; 6(4):275-280. [PubMed: 3912343] 
13. Garralda ME, Jameson RA, Reynolds JM, Postlethwaite RJ. Psychiatric adjustment in children with chronic renal failure. Journal of child psychology and psychiatry, and allied disciplines 1988 Jan;29 (1):79-90.

14. Schwartz GJ, Haycock GB, Edelmann CM Jr, Spitzer A. A simple estimate of glomerular filtration rate in children derived from body length and plasma creatinine. Pediatrics 1976 Aug;58(2):259263. [PubMed: 951142]

15. Schwartz GJ, Furth S, Cole SR, Warady B, Munoz A. Glomerular filtration rate via plasma iohexol disappearance: pilot study for chronic kidney disease in children. Kidney international 2006 Jun;69 (11):2070-2077. [PubMed: 16612328]

16. Schwartz GJ, Munoz A, Schneider MF, et al. New Equations to Estimate GFR in Children with CKD. J Am Soc Nephrol 2009 Mar;20(3):629-637. [PubMed: 19158356]

17. Varni JW, Burwinkle TM, Seid M, Skarr D. The PedsQL 4.0 as a pediatric population health measure: feasibility, reliability, and validity. Ambul Pediatr 2003 Nov-Dec;3(6):329-341. [PubMed: 14616041]

18. Varni JW, Seid M, Kurtin PS. PedsQL 4.0: reliability and validity of the Pediatric Quality of Life Inventory version 4.0 generic core scales in healthy and patient populations. Medical care 2001 Aug; 39(8):800-812. [PubMed: 11468499]

19. Feldman HI, Appel LJ, Chertow GM, et al. The Chronic Renal Insufficiency Cohort (CRIC) Study: Design and Methods. J Am Soc Nephrol 2003 Jul;14(7):S148-S153. [PubMed: 12819321]

20. Back SE, Krutzen E, Nilsson-Ehle P. Contrast media as markers for glomerular filtration: a pharmacokinetic comparison of four agents. Scandinavian journal of clinical and laboratory investigation 1988 May;48(3):247-253. [PubMed: 3375780]

21. Gaspari F, Perico N, Ruggenenti P, et al. Plasma clearance of nonradioactive iohexol as a measure of glomerular filtration rate. J Am Soc Nephrol 1995 Aug;6(2):257-263. [PubMed: 7579093]

22. Olsson B, Aulie A, Sveen K, Andrew E. Human pharmacokinetics of iohexol. A new nonionic contrast medium. Investigative radiology 1983 Mar-Apr;18(2):177-182. [PubMed: 6408018]

23. Krutzen E, Back SE, Nilsson-Ehle I, Nilsson-Ehle P. Plasma clearance of a new contrast agent, iohexol: a method for the assessment of glomerular filtration rate. The Journal of laboratory and clinical medicine 1984 Dec;104(6):955-961. [PubMed: 6438261]

24. Nilsson-Ehle P, Grubb A. New markers for the determination of GFR: iohexol clearance and cystatin C serum concentration. Kidney Int Suppl 1994 Nov;47:S17-S19. [PubMed: 7869664]

25. Sterner G, Frennby B, Mansson S, Ohlsson A, Prutz KG, Almen T. Assessing residual renal function and efficiency of hemodialysis--an application for urographic contrast media. Nephron 2000 Aug; 85(4):324-333. [PubMed: 10940743]

26. Frennby B, Sterner G, Almen T, Hagstam KE, Hultberg B, Jacobsson L. The use of iohexol clearance to determine GFR in patients with severe chronic renal failure--a comparison between different clearance techniques. Clinical nephrology 1995 Jan;43(1):35-46. [PubMed: 7697934]

27. Falkner B, Daniels SR. Summary of the Fourth Report on the Diagnosis, Evaluation, and Treatment of High Blood Pressure in Children and Adolescents. Hypertension 2004 Oct;44(4):387-388. [PubMed: 15353515]

28. Mitsnefes M, Ho PL, McEnery PT. Hypertension and progression of chronic renal insufficiency in children: a report of the North American Pediatric Renal Transplant Cooperative Study (NAPRTCS). J Am Soc Nephrol 2003 Oct;14(10):2618-2622. [PubMed: 14514740]

29. Clinical practice recommendations for anemia in chronic kidney disease in children. Am J Kidney Dis 2006 May;47(5):S86-S108. III.

30. Stone P, Richards M, Hardy J. Fatigue in patients with cancer. Eur J Cancer 1998 Oct;34(11):16701676. [PubMed: 9893650]

31. Hockenberry MJ, Hinds PS, Barrera P, et al. Three instruments to assess fatigue in children with cancer: the child, parent and staff perspectives. Journal of pain and symptom management 2003 Apr; 25(4):319-328. [PubMed: 12691683]

32. Petersen S, Bergstrom E, Brulin C. High prevalence of tiredness and pain in young schoolchildren. Scandinavian journal of public health 2003;31(5):367-374. [PubMed: 14555373]

33. Nagane M. Relationship of subjective chronic fatigue to academic performance. Psychological reports 2004 Aug;95(1):48-52. [PubMed: 15460357] 
34. Wilson A, Yu HT, Goodnough LT, Nissenson AR. Prevalence and outcomes of anemia in rheumatoid arthritis: a systematic review of the literature. The American journal of medicine $2004 \mathrm{Apr}$ 5;116:50S-57S. [PubMed: 15050886]

35. Jhamb M, Weisbord SD, Steel JL, Unruh M. Fatigue in patients receiving maintenance dialysis: a review of definitions, measures, and contributing factors. Am J Kidney Dis 2008 Aug;52(2):353365. [PubMed: 18572290]

36. McKenna AM, Keating LE, Vigneux A, Stevens S, Williams A, Geary DF. Quality of life in children with chronic kidney disease-patient and caregiver assessments. Nephrol Dial Transplant 2006 Jul;21 (7):1899-1905. [PubMed: 16611686]

37. Goldstein SL, Gerson AC, Goldman CW, Furth S. Quality of life for children with chronic kidney disease. Seminars in nephrology 2006 Mar;26(2):114-117. [PubMed: 16530604]

38. Naughton MJ, Ruggiero AM, Lawrence JM, et al. Health-related quality of life of children and adolescents with type 1 or type 2 diabetes mellitus: SEARCH for Diabetes in Youth Study. Archives of pediatrics \& adolescent medicine 2008 Jul;162(7):649-657. [PubMed: 18606936]

39. Varni JW, Limbers CA. The PedsQL Multidimensional Fatigue Scale in young adults: feasibility, reliability and validity in a University student population. Qual Life Res 2008 Feb;17(1):105-114. [PubMed: 18027106]

40. Chervin RD, Hedger K, Dillon JE, Pituch KJ. Pediatric sleep questionnaire (PSQ): validity and reliability of scales for sleep-disordered breathing, snoring, sleepiness, and behavioral problems. Sleep medicine 2000 Feb 1;1(1):21-32. [PubMed: 10733617]

41. Owens JA, Spirito A, McGuinn M. The Children's Sleep Habits Questionnaire (CSHQ): psychometric properties of a survey instrument for school-aged children. Sleep 2000 Dec 15;23(8):1043-1051. [PubMed: 11145319]

42. Archbold KH, Pituch KJ, Panahi P, Chervin RD. Symptoms of sleep disturbances among children at two general pediatric clinics. The Journal of pediatrics 2002 Jan;140(1):97-102. [PubMed: 11815771]

43. Camhi SL, Morgan WJ, Pernisco N, Quan SF. Factors affecting sleep disturbances in children and adolescents. Sleep medicine 2000 Apr 1;1(2):117-123. [PubMed: 10767652]

44. Viner R, Christie D. Fatigue and somatic symptoms. BMJ (Clinical research ed 2005 Apr 30;330 (7498):1012-1015.

45. ter Wolbeek M, van Doornen LJ, Kavelaars A, Heijnen CJ. Severe fatigue in adolescents: a common phenomenon? Pediatrics 2006 Jun;117(6):e1078-e1086. [PubMed: 16740810] 


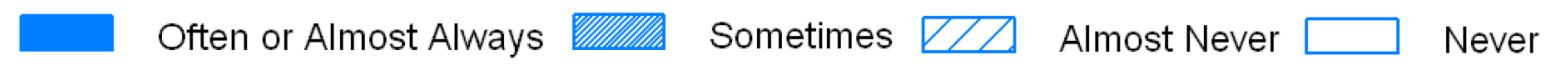

A Child Report of Trouble Sleeping

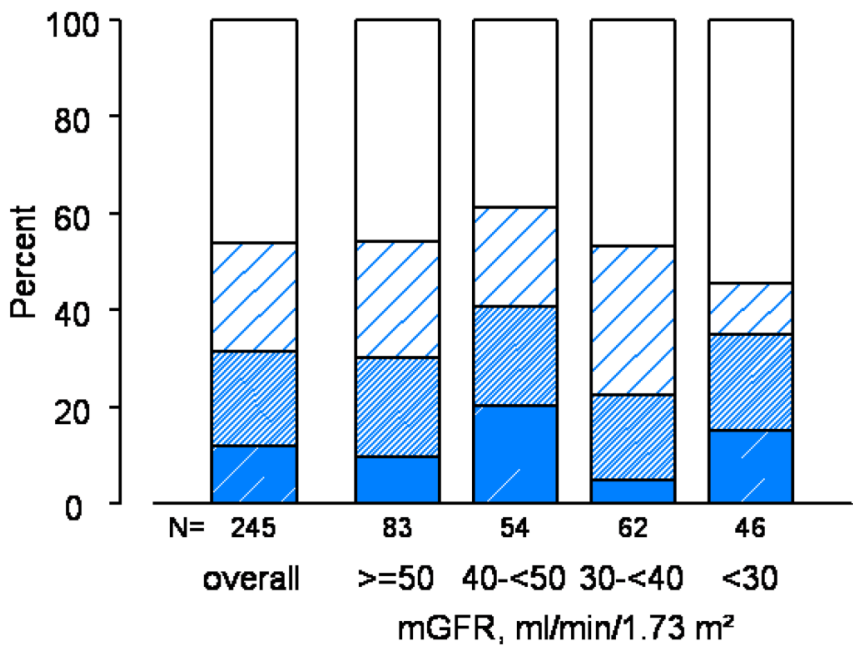

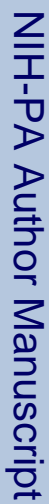

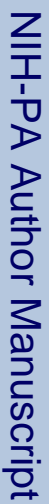

C Child Report of Low Energy

Figure 1. PedsQL outcomes overall and by mGFR level.
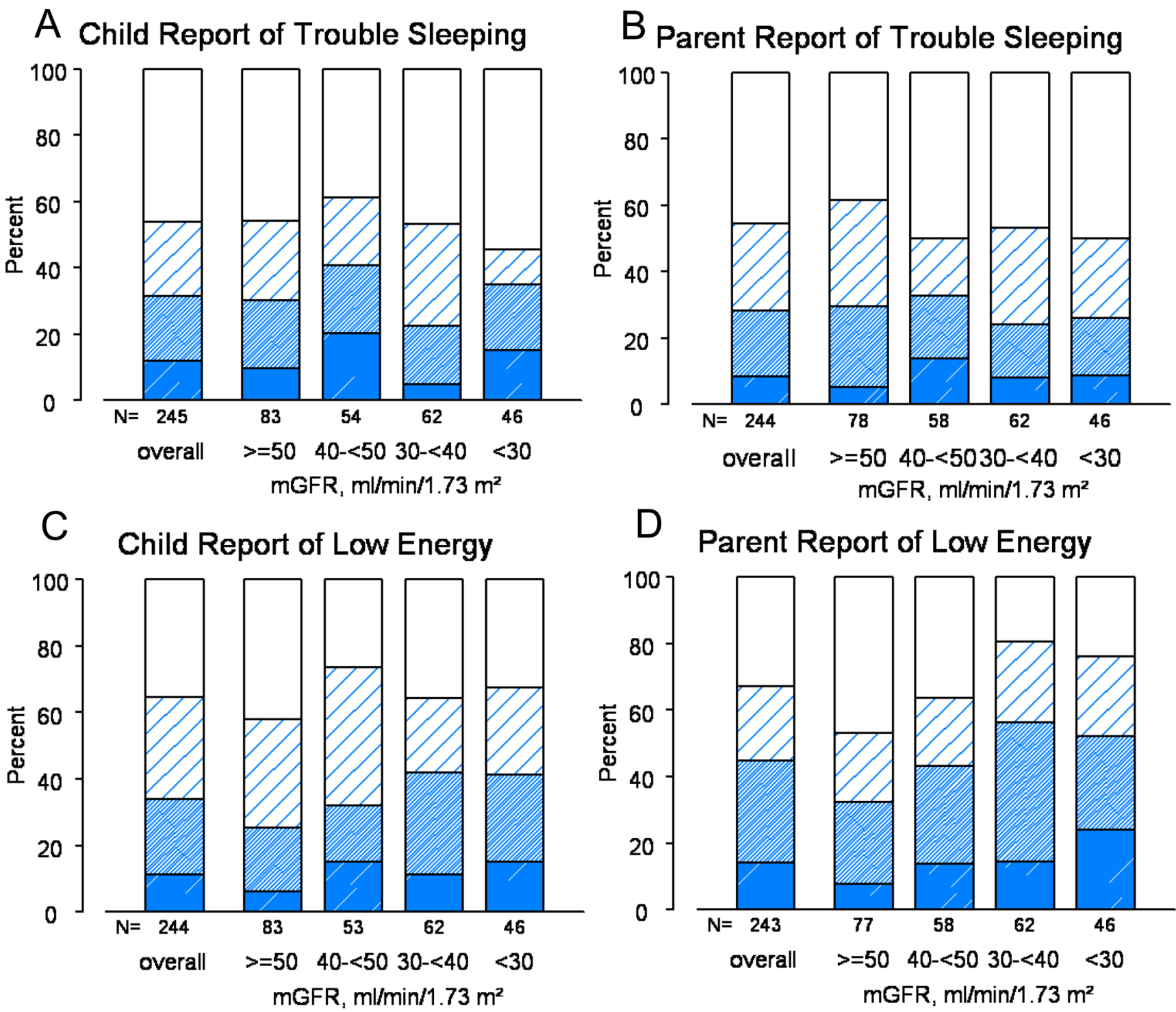

D Parent Report of Low Energy

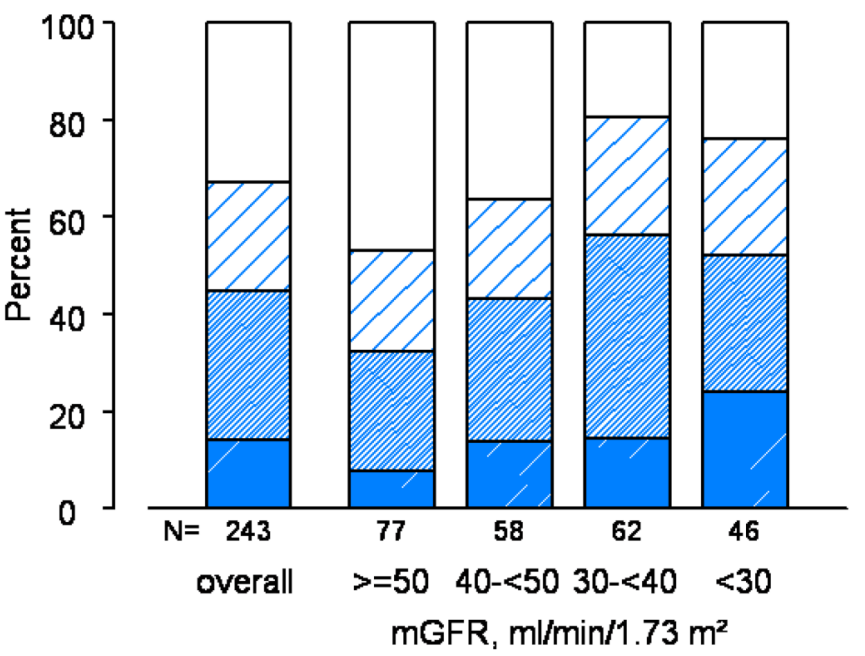

Distribution of child report of trouble sleeping (panel A), parent report of trouble sleeping (panel B), child report of low energy (panel C), and parent report of low energy (panel D) 

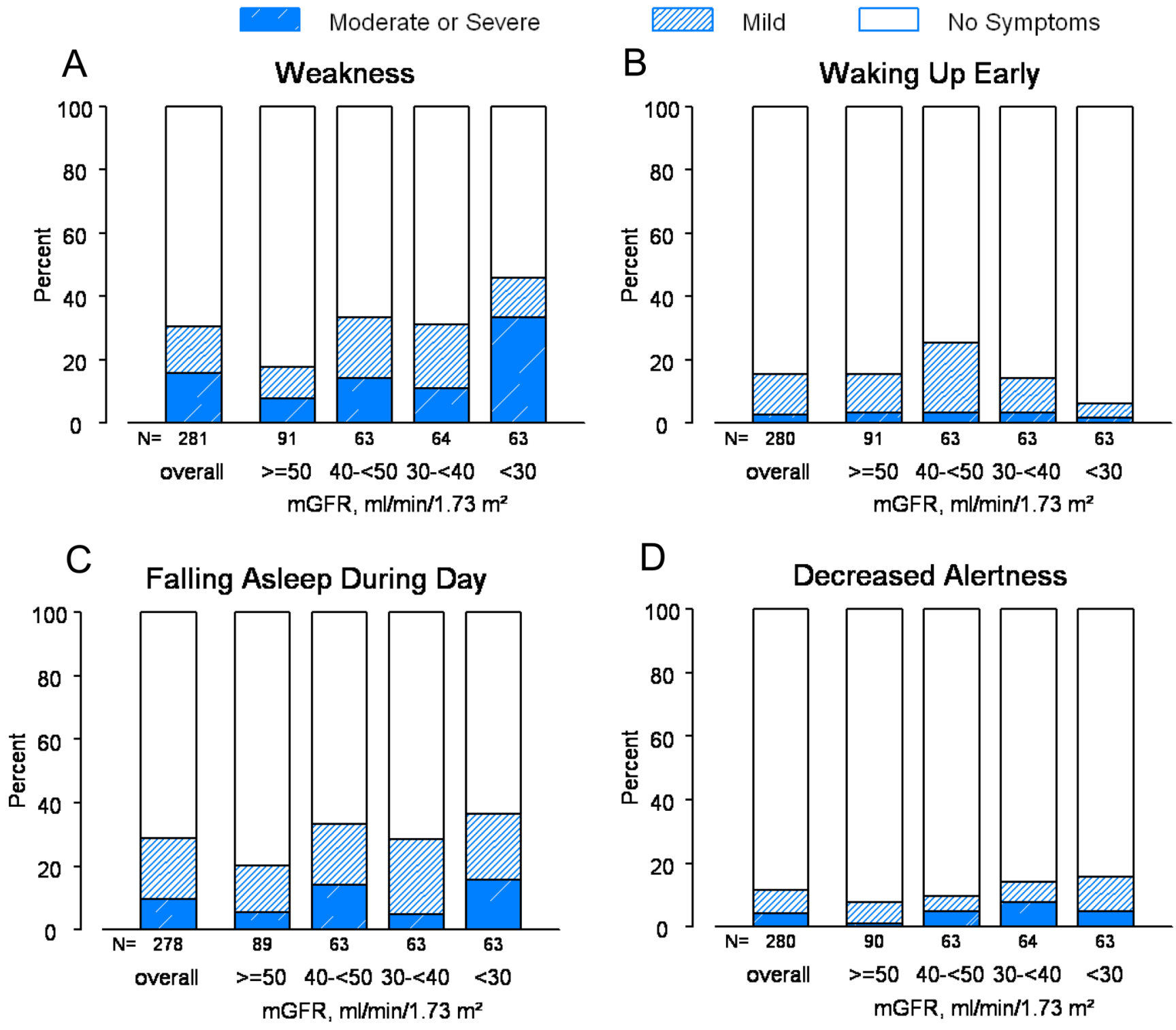

Figure 2.

Distribution of child report of weakness (panel A), waking up early (panel B), falling asleep during the day (panel C), and decreased alertness (panel D) CKD-related symptoms overall and by mGFR level. 


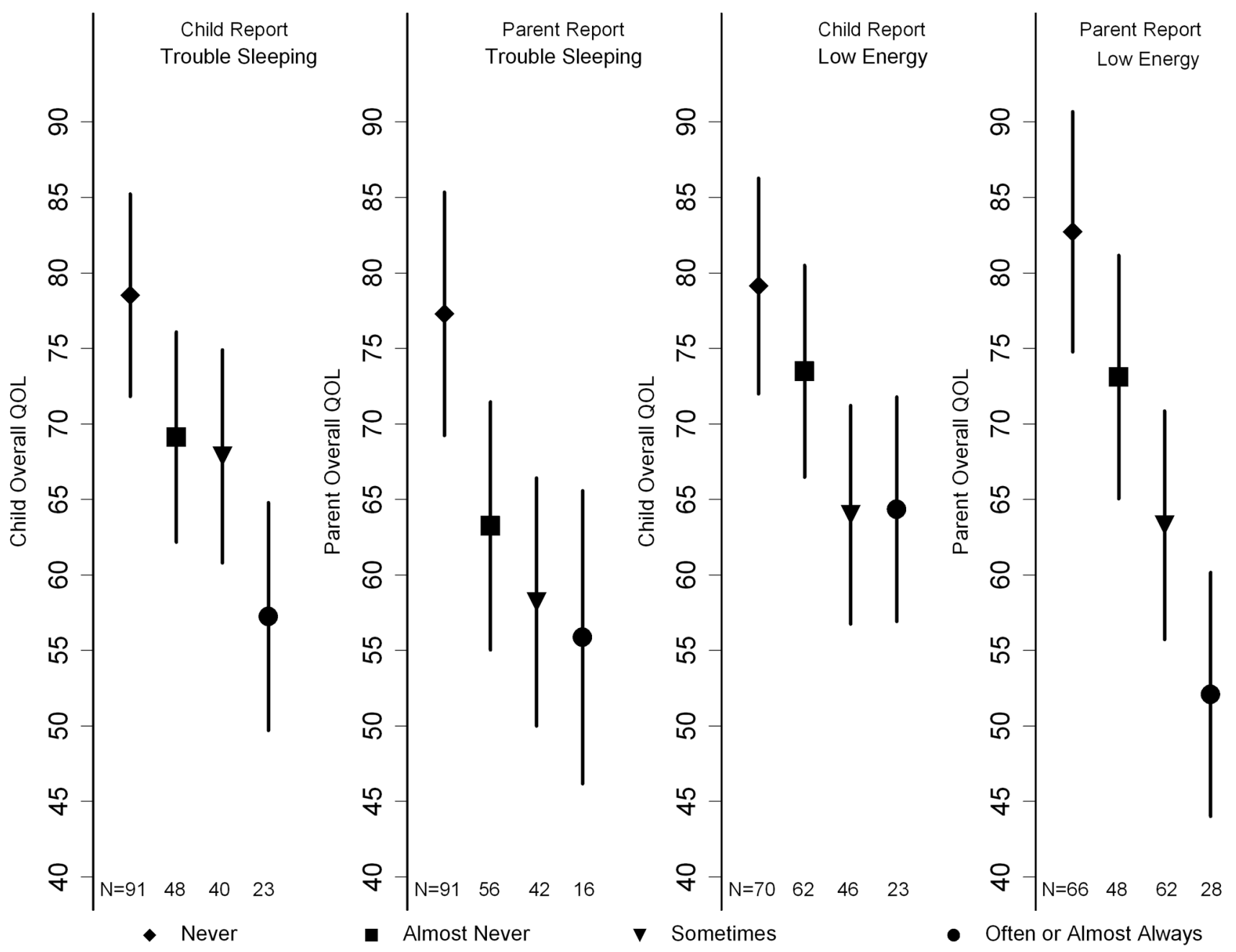

Figure 3.

Adjusted estimated Quality of Life scores by child report of trouble sleeping (panel A) and parent report of trouble sleeping (panel B), and by child report of low energy (panel C) and parent report of low energy (panel D). Values reported are mean child and parent Quality Of Life scores and $95 \%$ confidence intervals after adjusting for age, sex, mGFR stage, income, percentage of life with CKD, BMI percentile, low birth weight, hypertension and anemia. A report of "often" or "almost always" having trouble sleeping was associated with lower PedsQL scores (mean of 57.2 compared to means of $78.5[\mathrm{P}<0.001], 69.1[\mathrm{P}<0.001]$ and $67.8[\mathrm{P}=0.001]$ when "never," "almost never," or "sometimes" were reported by the child, respectively, and a mean of 55.9 vs. $77.3[\mathrm{P}<0.001], 63.2[\mathrm{P}=0.06]$ and $58.2[\mathrm{P}=0.6]$ when "never, "almost never," or "sometimes" were reported by the parent, respectively). A report of "often" or "almost always" having lower energy was also associated with lower PedsQL scores (mean of 64.3 vs. $79.1[\mathrm{P}<0.001], 73.5[\mathrm{P}=0.003]$ and $64.0[\mathrm{P}<0.001]$ when "never," "almost never" or "sometimes" were reported by the child, respectively, and a mean of 52.1 vs. 82.7 [P $<0.001]$, $73.1[\mathrm{P}<0.001]$ and $63.3[\mathrm{P}<0.001]$ when "never," "almost never" or "sometimes" were reported by the parent, respectively). 


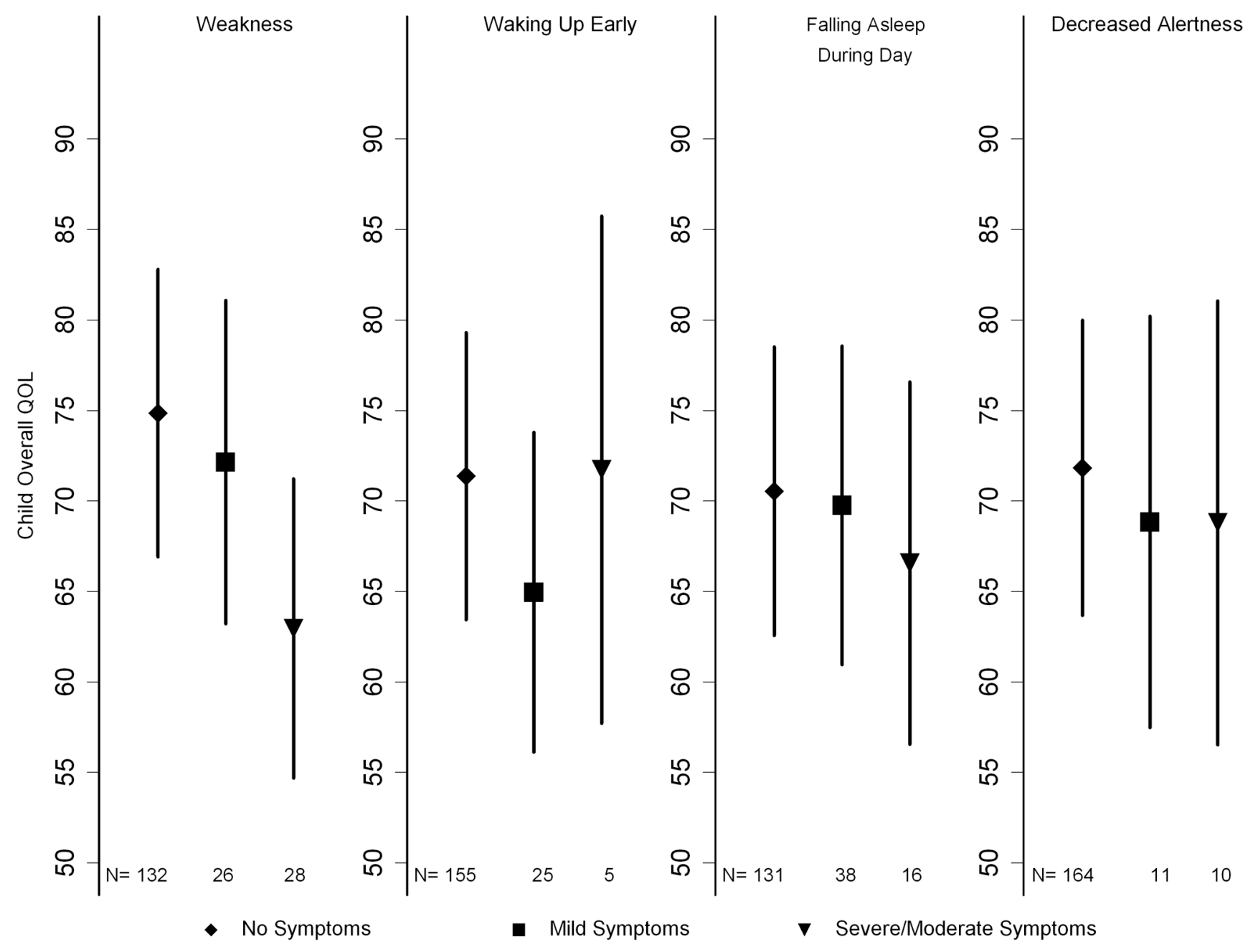

Figure 4.

Adjusted estimated child Quality Of Life scores by parent and/or child report of symptom severity for weakness (panel A), waking up too early (panel B), falling asleep during the day (panel C) and decreased alertness (panel D). Values reported are mean child Quality of Life scores and $95 \%$ confidence intervals after adjusting for age, sex, mGFR stage, income, percentage of life with CKD, BMI percentile, hypertension and anemia. A report of "moderate" or "severe" weakness was associated with lower quality of life (mean of 63.0 vs. 74.8 [P<0.001] and $72.1[\mathrm{P}=0.01]$ when "no" symptoms or "mild" symptoms were reported). None of the other symptoms were associated with the childrens' overall PedsQL scores. 
Table 1

Characteristics of participants in the CKiD Study

\begin{tabular}{|c|c|c|}
\hline & $\begin{array}{l}\text { No. of participants } \\
\text { with data available }\end{array}$ & $\begin{array}{l}\text { Median (25th, } 75 \text { th percentile) or } \\
\text { No. }(\%)\end{array}$ \\
\hline Age, yr & 301 & $13.9(10.8,16.2)$ \\
\hline Male Sex & 301 & $183(61)$ \\
\hline White Race & 301 & $218(72)$ \\
\hline $\begin{array}{l}\text { Annual Income of primary } \\
\text { household members }\end{array}$ & 285 & \\
\hline$\leq \$ 36,000$ & & $104(36)$ \\
\hline$\$ 36,001-\$ 75,000$ & & $89(31)$ \\
\hline$>\$ 75,000$ & & $92(32)$ \\
\hline $\begin{array}{l}\text { Measured GFR }(\mathrm{ml} / \mathrm{min} \text { per } \\
\left.1.73 \mathrm{~m}^{2}\right)\end{array}$ & 301 & \\
\hline$\geq 50$ & & $99(33)$ \\
\hline $40-<50$ & & $65(22)$ \\
\hline $30-<40$ & & $70(23)$ \\
\hline$<30$ & & $67(22)$ \\
\hline Years with CKD & 298 & $9.3(5.0,12.6)$ \\
\hline Primary CKD Diagnosis & 298 & \\
\hline GN diagnosis* & & $70(23)$ \\
\hline $\begin{array}{l}\text { non-GN (genitor-urinary, } \\
\text { cystic, hereditary) }\end{array}$ & & $207(69)$ \\
\hline non-GN (other) & & $21(7)$ \\
\hline Hypertension & 301 & $148(49)$ \\
\hline $\begin{array}{l}\text { SBP } \geq 95 \text { th percentile for age, } \\
\text { gender, height }\end{array}$ & 288 & $34(12)$ \\
\hline $\begin{array}{l}\text { DBP } \geq 95 \text { th percentile for age, } \\
\text { gender, height }\end{array}$ & 289 & $31(11)$ \\
\hline Anemia & 292 & $127(43)$ \\
\hline Hemoglobin $(\mathrm{g} / \mathrm{dL})$ & 292 & $12.6(11.6,13.6)$ \\
\hline Birth Weight $<2500 \mathrm{~g}$ & 285 & $48(17)$ \\
\hline \multicolumn{3}{|l|}{ Growth Markers } \\
\hline $\begin{array}{l}\text { Weight percentile for age and } \\
\text { sex }\end{array}$ & 301 & $44.3(19.0,77.6)$ \\
\hline $\begin{array}{l}\text { Height percentile for age and } \\
\text { sex }\end{array}$ & 293 & $24.7(8.0,51.4)$ \\
\hline BMI percentile for age and sex & 293 & $56.7(34.3,86.1)$ \\
\hline Tanner Stage & 286 & \\
\hline I & & $95(33)$ \\
\hline II & & $47(16)$ \\
\hline III & & $31(11)$ \\
\hline IV & & $59(21)$ \\
\hline $\mathrm{V}$ & & $54(19)$ \\
\hline
\end{tabular}




\begin{tabular}{|l|l|l|}
\hline & $\begin{array}{l}\text { No. of participants } \\
\text { with data available }\end{array}$ & $\begin{array}{l}\text { Median (25th, 75th percentile) } \text { or } \\
\text { No. (\%) }\end{array}$ \\
\hline Medication Usage & 301 & \\
\hline Anti-hypertensives & & $221(73)$ \\
\hline ESAs & & $53(18)$ \\
\hline Growth Hormones & & $37(12)$ \\
\hline Immunosuppressives & & $35(12)$ \\
\hline Corticosteroids & & $19(6)$ \\
\hline CNS-stimulating agents & & $15(5)$ \\
\hline Antidepressants & & $13(4)$ \\
\hline
\end{tabular}

$\mathrm{N}=301$.

Abbreviations: GFR, glomerular filtration rate; GN, glomerulonephritis; Conversion factors for units: GFR in $\mathrm{mL} / \mathrm{min} / 1.73 \mathrm{~m}^{2}$ to $\mathrm{mL} / \mathrm{s} / 1.73 \mathrm{~m}^{2}$, $\times 0.01667 ;$ Hemoglobin in $\mathrm{g} / \mathrm{dL}$ to $\mathrm{g} / \mathrm{L}, \times 10$.

*

* Of the 70 participants with glomerulonephritis as cause of CKD: 23 have focal segmental glomerulosclerosis, 12 have hemolytic uremic syndrome, 5 have familial nephritis (Alport's), 5 have IgA nephropathy (Berger's), 5 have systemic immunological disease, 3 have chronic glomerulonephritis, 3 have membranoproliferative glomerulonephritis type I, 2 have idiopathic crescentic glomerulonephritis, 2 have congenital nephritic syndrome, 1 has membranous nephropathy, 1 has henoch schoenlein purpura, 1 has membranoproliferative glomerulonephritis type II, 7 have other glomerular causes of CKD. 


\section{Table 2}

Multivariate Relationships between Pediatric Quality of Life Inventory outcomes and cohort characteristics.

\begin{tabular}{|c|c|c|c|c|}
\hline & \multicolumn{2}{|c|}{ Trouble Sleeping } & \multicolumn{2}{|c|}{ Low Energy } \\
\hline & $\begin{array}{c}\text { Child Report } \\
\% \text {; OR (95\% } \\
\text { CI) }\end{array}$ & $\begin{array}{c}\text { Parent } \\
\text { Report } \\
\% ; \text { OR }(95 \% \\
\text { CI })\end{array}$ & $\begin{array}{c}\text { Child Report } \\
\% \text {; OR (95\% } \\
\text { CI) }\end{array}$ & $\begin{array}{c}\text { Parent Report } \\
\% ; \text { OR }(95 \% \text { CI })\end{array}$ \\
\hline No. & No. $=237$ & No. $=214$ & No. $=234$ & No. $=222$ \\
\hline \multicolumn{5}{|l|}{ Measured GFR ${ }^{a}$} \\
\hline$\geq 50$ & $33 \% ; 1$ (ref) & $29 \% ; 1$ (ref) & $33 \% ; 1$ (ref) & $31 \% ; 1$ (ref) \\
\hline $40-<50$ & $\begin{array}{c}23 \% ; 1.49 \\
(0.78,2.83)\end{array}$ & $\begin{array}{l}23 \% ; 0.88 \\
(0.44,1.77)\end{array}$ & $\begin{array}{l}22 \% ; 1.38 \\
(0.72,2.65)\end{array}$ & $24 \% ; 2.07(1.05,4.09)^{*}$ \\
\hline $30-<40$ & $\begin{array}{l}26 \% ; 0.92 \\
(0.49,1.73)\end{array}$ & $\begin{array}{l}28 \% ; 0.75 \\
(0.37,1.51)\end{array}$ & $\begin{array}{l}26 \% ; 1.12 \\
(0.58,2.17)\end{array}$ & $27 \% ; 2.35(1.17,4.72)^{*}$ \\
\hline$<30$ & $\begin{array}{c}19 \% ; 0.93 \\
(0.46,1.90)\end{array}$ & $\begin{array}{l}20 \% ; 0.77 \\
(0.34,1.75)\end{array}$ & $\begin{array}{c}19 \% ; 1.49 \\
(0.70,3.17)\end{array}$ & $18 \% ; 2.59(1.15,5.85)^{*}$ \\
\hline \multicolumn{5}{|l|}{ Family Income } \\
\hline$\leq \$ 36,000$ & NA & $37 \% ; 1$ (ref) & $\mathrm{NA}$ & $37 \% ; 1$ (ref) \\
\hline$\$ 36,000-\leq \$ 75,000$ & $\mathrm{NA}$ & $\begin{array}{l}30 \% ; 0.82 \\
(0.44,1.52)\end{array}$ & $\mathrm{NA}$ & $31 \% ; 0.82(0.44,1.50)$ \\
\hline$>\$ 75,000$ & NA & $\begin{array}{c}33 \% ; 0.54 \\
(0.30,0.99)\end{array}$ & NA & $32 \% ; 0.32(0.16,0.67)^{*}$ \\
\hline \multicolumn{5}{|l|}{$\%$ of life with CKD } \\
\hline$<25 \%$ & NA & $\mathrm{NA}$ & $17 \% ; 1$ (ref) & $16 \% ; 1$ (ref) \\
\hline $25 \%$ to $<75 \%$ & NA & NA & $\begin{array}{c}30 \% ; 0.35 \\
(0.17,0.71)^{*}\end{array}$ & $29 \% ; 0.47(0.22,1.02)$ \\
\hline $75 \%$ to $100 \%$ & NA & NA & $\begin{array}{c}53 \% ; 0.34 \\
(0.17,0.65)^{*}\end{array}$ & $55 \% ; 0.32(0.16,0.67)^{*}$ \\
\hline \multicolumn{5}{|l|}{ Growth Markers } \\
\hline Birth Weight $<2500 \mathrm{~g}^{* *}$ & NA & $\begin{array}{c}18 \% ; 1.55 \\
(0.81,2.95)\end{array}$ & $\mathrm{NA}$ & NA \\
\hline \multicolumn{5}{|l|}{ BMI percentile ${ }^{b}$} \\
\hline$<35$ & $26 \% ; 1$ (ref) & NA & NA & NA \\
\hline 35 to $<60$ & $\begin{array}{l}23 \% ; 1.16 \\
(0.59,2.30)\end{array}$ & NA & $\mathrm{NA}$ & NA \\
\hline 60 to $<85$ & $\begin{array}{l}24 \% ; 0.90 \\
(0.45,1.79)\end{array}$ & NA & NA & NA \\
\hline$\geq 85$ & $\begin{array}{c}27 \% ; 1.96 \\
(1.01,3.83)^{*}\end{array}$ & NA & $\mathrm{NA}$ & NA \\
\hline \multicolumn{5}{|l|}{ Co-morbidities } \\
\hline Hypertensive $^{b}$ & $\begin{array}{c}48 \% ; 0.59 \\
(0.36,0.97)^{*}\end{array}$ & NA & NA & NA \\
\hline Anemia & NA & $\begin{array}{l}45 \% ; 1.03 \\
(0.58,1.81)\end{array}$ & $\begin{array}{l}41 \% ; 1.66 \\
(0.96,2.85)\end{array}$ & $44 \% ; 1.75(0.99,3.09)$ \\
\hline $\begin{array}{l}\text { Global P-value for model } \\
\text { significance }\end{array}$ & $\mathrm{P}=0.07$ & $\mathrm{P}=0.4$ & $\mathrm{P}=0.005$ & $\mathrm{P}<0.001$ \\
\hline
\end{tabular}


* indicates significance at the 0.05 level; OR, odds ratio; CI, confidence interval; CKD, chronic kidney disease; NA, not applicable; ref, reference. ** reference value is $\geq 2500 \mathrm{~g}[\mathrm{ND} 3]$

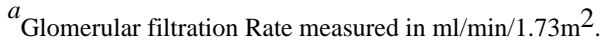

${ }^{b}$ Age and sex specific percentiles using standard growth charts for United States children.

${ }^{b}$ Systolic or Diastolic Blood Pressure $>95^{\text {th }}$ percentile for age, sex, height or self-report of hypertension with concurrent report of anti-hypertensive medication. 
Table 3

Multivariate Relationships between Chronic Kidney Disease-related symptoms and cohort characteristics

\begin{tabular}{|c|c|c|c|c|}
\hline & $\begin{array}{c}\text { Weakness } \\
\text { \% OR }(95 \% \text { CI })\end{array}$ & $\begin{array}{l}\text { Waking Up } \\
\text { Early } \\
\% \text { OR (95\% } \\
\text { CI) }\end{array}$ & $\begin{array}{l}\text { Falling Asleep } \\
\text { during the day } \\
\% \text { OR }(95 \% \text { CI })\end{array}$ & $\begin{array}{c}\text { Decreased } \\
\text { Alertness } \\
\% \text { OR }(95 \% \\
\text { CI })\end{array}$ \\
\hline No. & No. $=224$ & No. $=264$ & No. $=246$ & No. $=268$ \\
\hline \multicolumn{5}{|l|}{ Measured GFR ${ }^{a}$} \\
\hline$\geq 50$ & $29 \% ; 1$ (ref) & $33 \% ; 1$ (ref) & $31 \% ; 1$ (ref) & $31 \% ; 1$ (ref) \\
\hline $40-<50$ & $\begin{array}{c}22 \% ; 2.08(0.79 \\
5.47)\end{array}$ & $\begin{array}{c}22 \% ; 2.29 \\
(0.99,5.32)\end{array}$ & $\begin{array}{c}21 \% ; 2.95(1.26 \\
6.88)^{*}\end{array}$ & $\begin{array}{c}23 \% ; 1.02 \\
(0.31,3.36)\end{array}$ \\
\hline $30-<40$ & $\begin{array}{c}26 \% ; 1.60(0.59 \\
4.37)\end{array}$ & $\begin{array}{l}24 \% ; 1.13 \\
(0.44,2.88)\end{array}$ & $\begin{array}{c}25 \% ; \\
4.77)\end{array}$ & $\begin{array}{l}23 \% ; 1.44 \\
(0.46,4.48)\end{array}$ \\
\hline$<30$ & $\begin{array}{c}23 \% ; 3.92(1.37 \\
11.17)^{*}\end{array}$ & $\begin{array}{l}22 \% ; 0.36 \\
(0.10,1.34)\end{array}$ & $\begin{array}{c}23 \% ; 2.15(0.83, \\
5.57)\end{array}$ & $\begin{array}{c}23 \% ; 1.40 \\
(0.41,4.74)\end{array}$ \\
\hline \multicolumn{5}{|l|}{ Demographics } \\
\hline \multicolumn{5}{|l|}{ Age (years) } \\
\hline 8 to $\leq 11$ & NA & NA & $30 \% ; 1$ (ref) & $28 \% ; 1$ (ref) \\
\hline$>11$ to $\leq 14$ & NA & NA & $\begin{array}{c}24 \% ; 1.59(0.65, \\
3.89)\end{array}$ & $\begin{array}{c}24 \% ; 3.50 \\
(0.98,12.57)\end{array}$ \\
\hline$>14$ to $\leq 16$ & NA & NA & $\begin{array}{c}21 \% ; 4.34(1.63 \\
11.60)^{*}\end{array}$ & $\begin{array}{c}22 \% ; 3.07 \\
(0.86,10.96)\end{array}$ \\
\hline$>16$ & NA & NA & $\begin{array}{c}26 \% ; 5.27(1.75 \\
15.85)^{*}\end{array}$ & $\begin{array}{c}26 \% ; 2.44 \\
(0.68,8.67)\end{array}$ \\
\hline non-White Race & NA & NA & NA & $\begin{array}{c}26 \% ; 1.71 \\
(0.72,4.05)\end{array}$ \\
\hline \multicolumn{5}{|l|}{ Family Income } \\
\hline$\leq \$ 36,000$ & $36 \% ; 1$ (ref) & $37 \% ; 1$ (ref) & $37 \% ; 1$ (ref) & NA \\
\hline$\$ 36,000-<\$ 75,000$ & $\begin{array}{c}31 \% ; 0.44(0.20 \\
0.97)^{*}\end{array}$ & $\begin{array}{c}31 \% ; 0.52 \\
(0.21,1.29)\end{array}$ & $\begin{array}{c}31 \% ; 0.47(0.22 \\
0.98)\end{array}$ & NA \\
\hline$>\$ 75,000$ & $\begin{array}{c}33 \% ; 0.39(0.17 \\
0.89)^{*}\end{array}$ & $\begin{array}{c}31 \% ; 0.90 \\
(0.41,1.98)\end{array}$ & $\begin{array}{c}32 \% ; 0.51(0.25 \\
1.02)\end{array}$ & NA \\
\hline \multicolumn{5}{|l|}{$\%$ of life with CKD } \\
\hline$<25 \%$ & $17 \% ; 1$ (ref) & NA & NA & $17 \% ; 1$ (ref) \\
\hline $25 \%$ to $<75 \%$ & $\begin{array}{c}26 \% ; 0.18(0.07 \\
0.51)^{*}\end{array}$ & NA & NA & $\begin{array}{c}29 \% ; 0.73 \\
(0.26,2.04)\end{array}$ \\
\hline $75 \%$ to $100 \%$ & $\begin{array}{c}56 \% ; 0.29(0.13 \\
0.68)^{*}\end{array}$ & NA & NA & $\begin{array}{c}54 \% ; 0.55 \\
(0.20,1.48)\end{array}$ \\
\hline \multicolumn{5}{|l|}{ Growth Markers } \\
\hline Birth Weight $<2500 \mathrm{~g}^{* *}$ & $\begin{array}{c}19 \% ; 2.74(1.23 \\
6.06)^{*}\end{array}$ & NA & NA & NA \\
\hline \multicolumn{5}{|l|}{ BMI percentile $b$} \\
\hline$<35$ & $25 \% ; 1$ (ref) & NA & NA & NA \\
\hline 35 to $<60$ & $\begin{array}{c}26 \% ; 0.79(0.33 \\
1.87)\end{array}$ & NA & NA & NA \\
\hline
\end{tabular}




\begin{tabular}{|c|c|c|c|c|}
\hline & $\begin{array}{c}\text { Weakness } \\
\% \text { OR }(95 \% \text { CI })\end{array}$ & $\begin{array}{c}\text { Waking Up } \\
\text { Early } \\
\% \text { OR (95\% } \\
\text { CI) }\end{array}$ & $\begin{array}{l}\text { Falling Asleep } \\
\text { during the day } \\
\% \text { OR }(95 \% \text { CI })\end{array}$ & $\begin{array}{c}\text { Decreased } \\
\text { Alertness } \\
\% \text { OR (95\% } \\
\text { CI) }\end{array}$ \\
\hline 60 to $<85$ & $\begin{array}{c}23 \% ; 0.84(0.33 \\
2.12)\end{array}$ & NA & NA & NA \\
\hline$\geq 85$ & $\begin{array}{c}26 \% ; 0.57(0.21, \\
1.50)\end{array}$ & NA & NA & NA \\
\hline Tanner Stage IV or V & $\begin{array}{c}37 \% ; 0.54(0.27, \\
1.10)\end{array}$ & NA & $\begin{array}{c}37 \% ; 0.56(0.24, \\
1.31)\end{array}$ & NA \\
\hline Anemia & $\begin{array}{c}44 \% ; 2.20(1.05 \\
4.63)^{*}\end{array}$ & NA & $\begin{array}{c}43 \% ; 1.33(0.68, \\
2.59)\end{array}$ & $\begin{array}{l}43 \% ; 1.88 \\
(0.77,4.55)\end{array}$ \\
\hline $\begin{array}{l}\text { Global P-value for model } \\
\text { significance }\end{array}$ & $\mathrm{P}<0.001$ & $\mathrm{P}=0.02$ & $\mathrm{P}=0.001$ & $\mathrm{P}=0.3$ \\
\hline
\end{tabular}

OR, odds ratio; CI, confidence interval; CKD, chronic kidney Disease; NA, not applicable.

${ }^{a}$ Glomerular filtration Rate measured in $\mathrm{ml} / \mathrm{min} / 1.73 \mathrm{~m}^{2}$.

${ }^{b}$ Age and sex specific percentiles using standard growth charts for United States children

*

indicates significance at the 0.05 level

$* *$

reference value is $\geq 2500 \mathrm{~g}$ 